\title{
Microstrip Patch Antenna towards Future of Communication
}

\author{
Arun Kumar Singh ${ }^{1 *}$, Rabindranath Bera', Bansibadan Maji ${ }^{2}$ and Riwas Gurung ${ }^{1}$ \\ 'Department of Electronics and Communication Engineering, Sikkim Manipal \\ Institute of Technology, Sikkim Manipal University, Majitar, Rangpo - 737132, Sikkim, India; \\ arunsingh.smit@gmail.com, rbera50@gmail.com \\ 2Department of Electronics and Communication Engineering, National Institute of \\ Technology, Durgapur - 713209, West Bengal, India; \\ bansibadan.maji@ece.nitdgp.ac.in, riwasgurung1994@gmail.com
}

\begin{abstract}
Objective: The aim of the design will be an antenna with higher gain and low return loss. The antenna is required to operate at $11 \mathrm{GHz}$. At this frequency there is special satellite communication such as DTH. In future large dish operating at above said frequency may get replaced by a small patch antenna (array). Method: To do this single patch design will not be helpful. Instead of this, array of patches will be required. The array can be of linear type or rectangular type. The best optimum design is to be selected. First a single antenna was prepared and optimized for the highest possible gain and resonating at desired frequency. The same was appended with array of different configurations in order to achieve the goal. Findings: Array design of linear type and rectangular type is proposed in this study. The antenna made is simulated for a wider range of frequencies from $8 \mathrm{GHz}$ to $14 \mathrm{GHz}$. The antenna was found to resonate at $11 \mathrm{GHz}$ and there is a considerable increase in gain also if the numbers of elements are increased. In this study the dimension of the antenna is diminished in comparison of the conventional one as the existing length and breadth of the substrate is modified and is shown lower section. Along with this in a particular design combination of series feed and corporate feed is shown which in turns improves the impedance matching of the antenna. This helps in better current distribution over all the patches. Application/Improvement: The proposed and designed antenna can be used for communication purpose in $\mathrm{X}$ band and further if the gain is improved to meet the gain characteristics of dish antenna ( $\mathrm{X}$ band) then it can be seen as a replacement of existing dish also.
\end{abstract}

Keywords: Array Antenna, Linear Array, Microstrip Patch Antenna (MPA), Rectangular Array, Return Loss

\section{Introduction}

Now days the larger size antenna is replaced by the antenna of smaller size popularly known as patch antenna. It finds its application in most of the fields starting from mobile communication to navigation. These kinds of antennas are inexpensive to fabricate because of its simple geometrical structure and due to this reason it is very popular amongst microwave designer since early days they appear $\stackrel{1,2}{~}$.

Communication in today's world is changed to wireless communication ${ }^{3}$. The term wireless is closely associated with an antenna as without antenna transmis- sion and reception of data is not possible ${ }^{4}$. In many cases the large size of the antenna makes it improper to be used in many applications. So as a result, attention is given towards compact microstrip patch antennas.

There are many shapes of patch like rectangular, circular, triangular etc. Moreover, hybrid shapes like E shape and $\mathrm{H}$ shape antennas are also coming into role now days ${ }^{5}$. The shape variation is simply because of its ease in fabrication as these kinds of antennas are low profile and inexpensive $e^{6,7}$. Patch antennas are usually fabricated over a substrate with a conducting ground plane ${ }^{6}$. The size of the patch and that of the substrate should be optimized accordingly so as to achieve the maximum performance.

${ }^{*}$ Author for correspondence 
In this study problem is focussed in comparison to dish antennas. The dish operating at $11 \mathrm{GHz}$ is having a diameter of around $60-75 \mathrm{~cm}$. With this dimension the portability of the device is poor.

The method shown in this study for antenna design will help to reduce the cost, size and weight of the antenna as larger dish will be replaced by patch antenna or in other words it will help to make to achieve reducing size, weight and power (SWaP) of the existing one. In this study, for the proposed model the gain achieved is nearly $15 \mathrm{~dB}$. It can be further increased if the number of elements is increased.

\section{Methodology}

In this study, the antenna is designed in $\mathrm{X}$ band particularly at $11 \mathrm{GHz}$. The relative permittivity of the substrate was 4.4. Width and length of the patch antenna is calculated using conventional formula. This is as shown below:

$$
\begin{gathered}
\text { Width }) \text { patch }=\frac{C}{2 f o \sqrt{((\epsilon r}+1) / 2)} \\
(\text { Length }) \text { patch }=\frac{C}{2 f 0 \sqrt{\epsilon e f f}} \\
+0.824 h \frac{(\epsilon \text { eff }+.3)\left(\frac{(\text { width }) \text { patch }}{h}+0.264\right)}{(\epsilon \text { eff }-0.258)\left(\frac{(\text { width }) \text { patch }}{h}+0.8\right)}
\end{gathered}
$$

Where $c$ is the velocity of light, for is the resonating frequency, $\in \mathrm{r}$ is the relative permittivity and $\mathrm{h}$ is the height of the dielectric substrate.

An important issue in microstrip patch antenna is the effectiveness of feed line. The length of the micro-strip feed can be calculated using (Paul, 2013)

$$
\text { (length })_{\text {feed }}=\frac{\lambda \mathrm{p}}{4 \sqrt{ } \varepsilon}
$$

Where $\lambda p$ the wavelength is related to MPA and $\varepsilon$ is the relative permittivity of the substrate used in the design.

Also for width of the feed
The effective dielectric constant $\in$ eff can be calculated from equation (3) $)^{1}$

$$
\in \text { eff }=\frac{\in r+1}{2}+\frac{\in r-1}{2}\left[1+12 \frac{\text { height }}{\text { width }}\right]^{\frac{-1}{2}}
$$

Where,

$\mathrm{Z}_{\text {in }}=$ input impedance,

$\in r=$ Dielectric constant of the substrate,

Height $=$ height of the substrate, and

Width = width of the patch.

Since the designs were made for $\mathrm{X}$ band at $11 \mathrm{GHz}$, the width and length of the patch was calculated as 8.30 $\mathrm{mm}$ and $5.75 \mathrm{~mm}$ respectively. The design schematic of single antenna is shown as Figure 1.

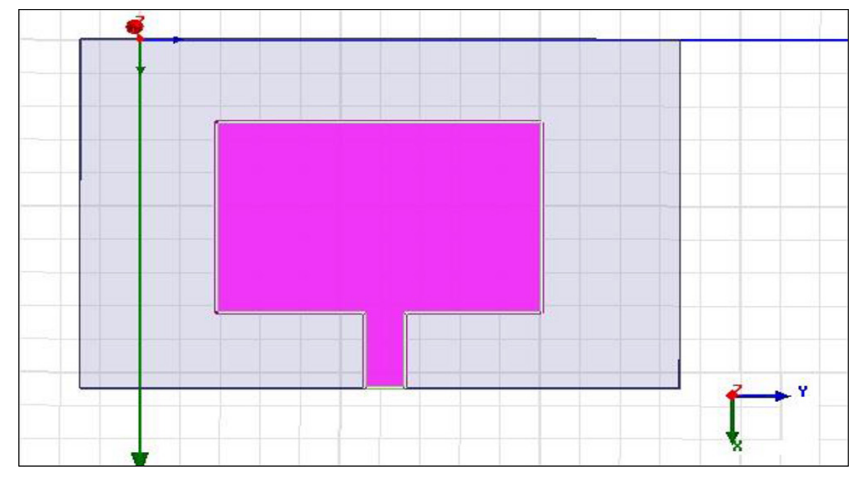

Figure 1. Simulation model of single patch @ 11GHz.

In the proposed model, the size of the ground is also reduced without any effect on the return loss and gain of the antenna. The actual length and width of the ground is given as

$$
L g=(6 \times h)+(\text { length }) \text { patch }
$$

and

$$
W g=(6 \times h)+(\text { Width }) \text { patch }
$$

Where Lg, lp, Wg, Wp are length of the ground, length of the patch, width of the ground and width of the patch respectively?

$$
Z_{\text {in }}=\frac{120 \pi}{\sqrt{ } \in \text { eff }\left[\frac{(\text { Width }) \text { feed }}{\text { height }}+1.393+0.667 \ln \left(\frac{(\text { Width }) \text { feed }}{\text { height }}+1.44\right)\right]}
$$


However, the length and width of ground used in the proposed model is:

$$
l g=(3 \times h)+(\text { length }) \text { patch }
$$

and

$$
W g=(4.5 \times h)+(\text { Width }) \text { patch }
$$

Equations $(6,7)$ are used throughout the modelling of the patch array.

Figure 2-4 shown is of fabricated different array antenna configuration.

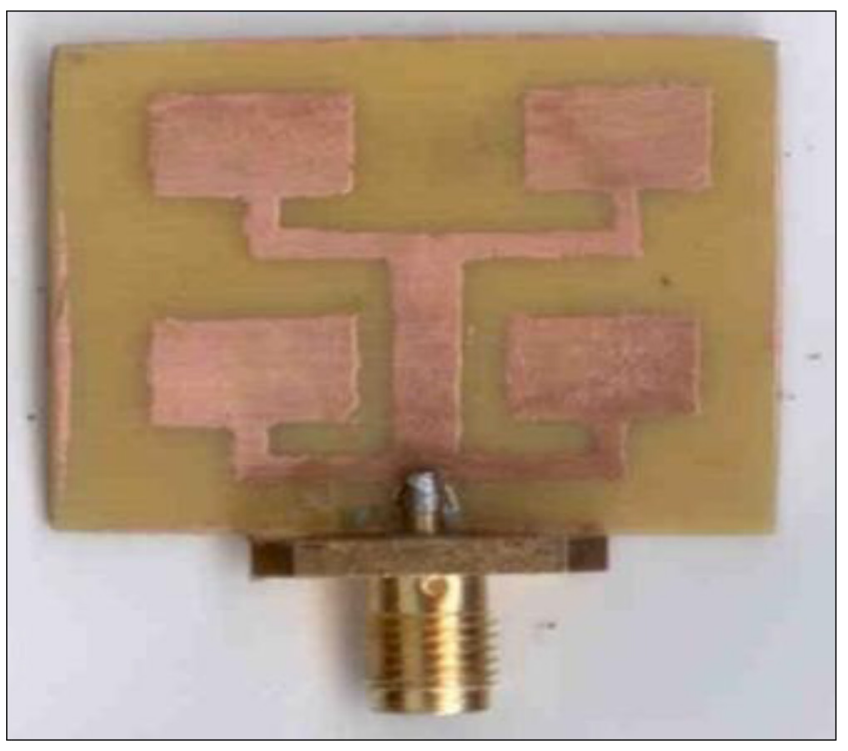

Figure 2. Microstrip patch array $2 \times 2$.

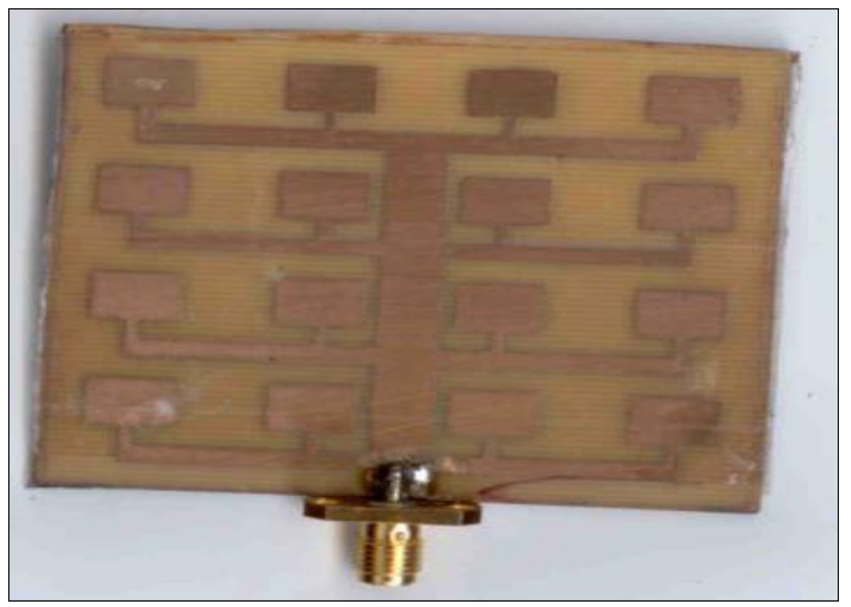

Figure 3. Microstrip patch array $4 \times 4$.

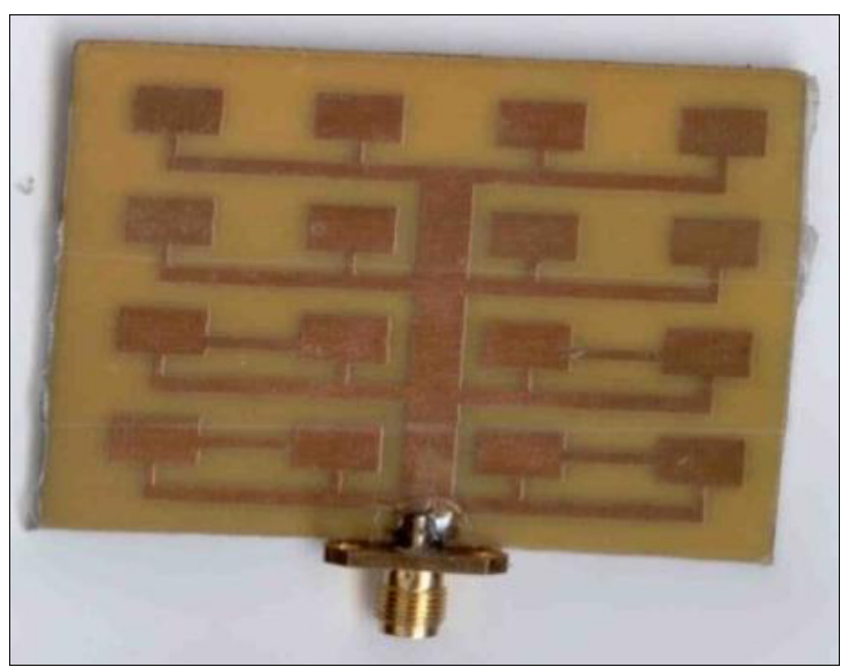

Figure 4. Modified.

\section{Results and Discussion}

Return loss (S11) parameter of single antenna (Figure 1) is shown in Figure 5. The return loss of $-29.2130 \mathrm{~dB}$ was observed to be at $11 \mathrm{GHz}$.

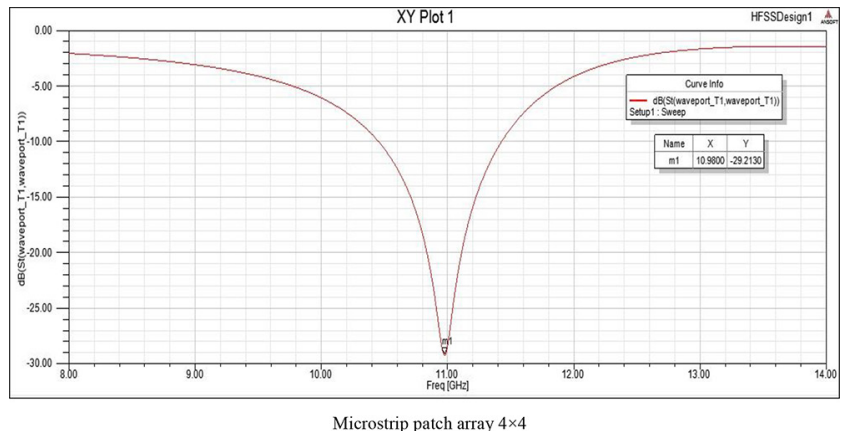

Figure 5. S11 parameter of single antenna for single patch shown in Figure 1.

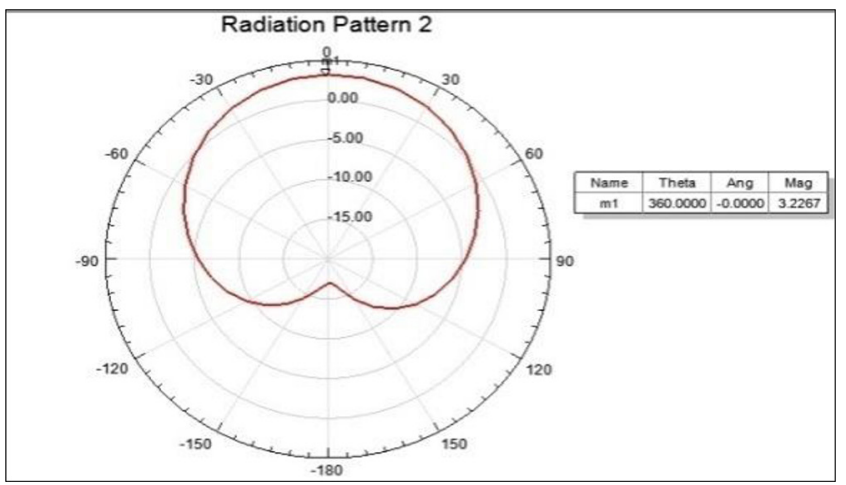

Figure 6. Radiation pattern of single patch shown in Figure 1. 
Figure 6-7 shows the radiation pattern and gain Vs frequency plot of single patch (Figure 1) antenna. The gain was observed to be $3.89 \mathrm{~dB}$ at $11 \mathrm{GHz}$.

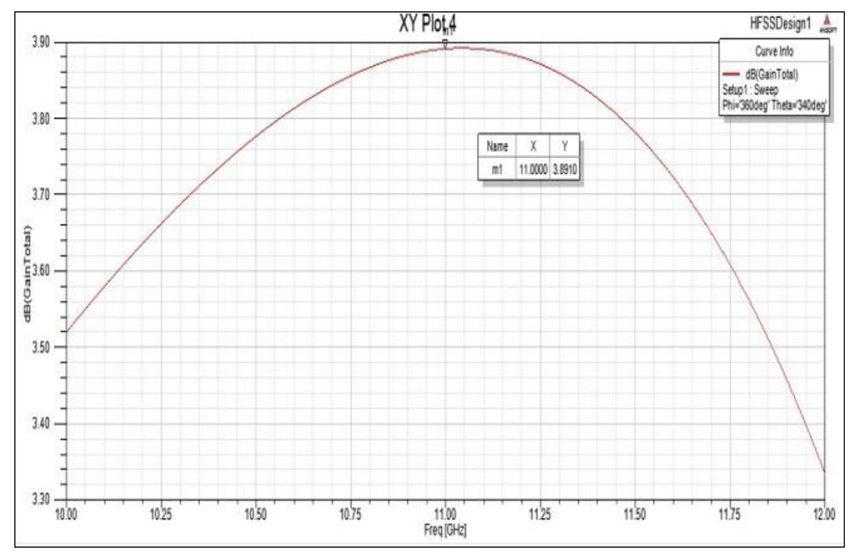

Figure 7. Gain Vs Frequency of single patch shown in Figure 1.

Figure 8-10 shows the S11 parameter, radiation pattern and gain characteristics of $2 \times 2$ patch array antenna (Figure 2) respectively. In the s11 parameter it's observed that the antenna is behaving like a multiband as the return loss is $-20.26 \mathrm{~dB}$ at $10.48 \mathrm{GHz}$ and $-44.895 \mathrm{~dB}$ at $11.5 \mathrm{GHz}$. The gain of the antenna is observed as 10.048 $\mathrm{dB} @ 11.5 \mathrm{GHz}$. Its corresponding actual hardware design is shown in Figure 2.

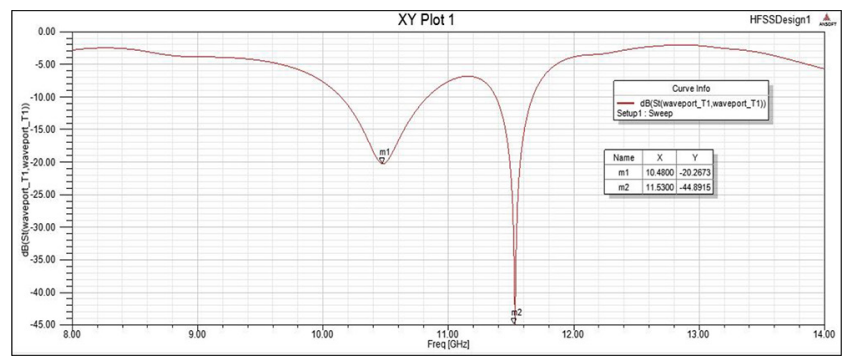

Figure 8. S11 parameter of $2 \times 2$ patch array antenna shown in Figure 2.

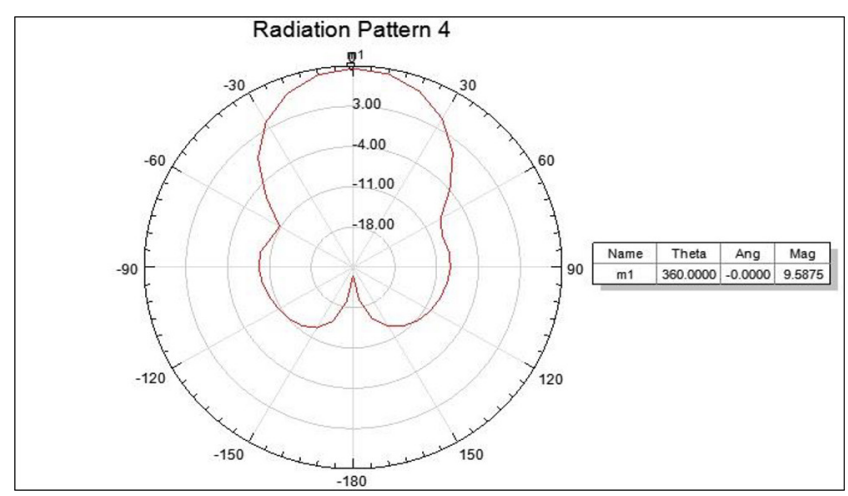

Figure 9. Radiation pattern of $2 \times 2$ patch array antenna.

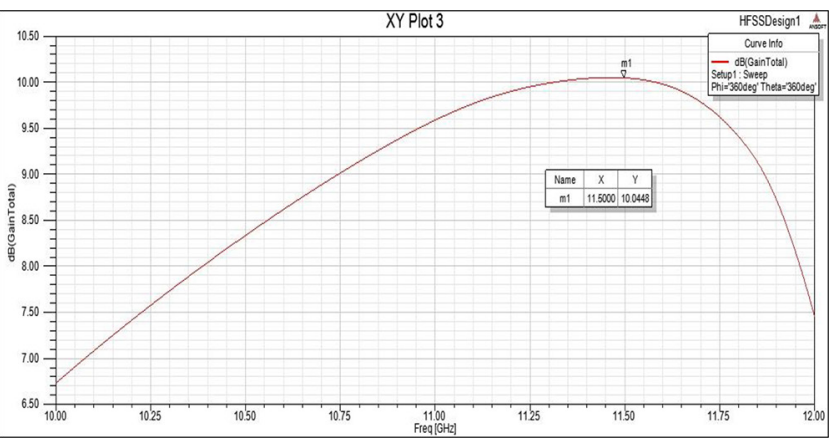

Figure 10. Gain Vs Frequency of $2 \times 2$ patch array antenna.

Figure 11-13 shows the s11 parameter, radiation pattern and gain Vs frequency plot for the design shown in

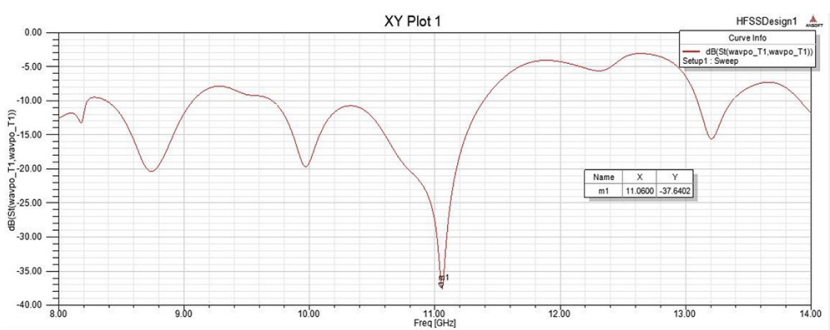

Figure 11. S11 parameter of $4 \times 4$ patch array antenna shown in Figure 3.

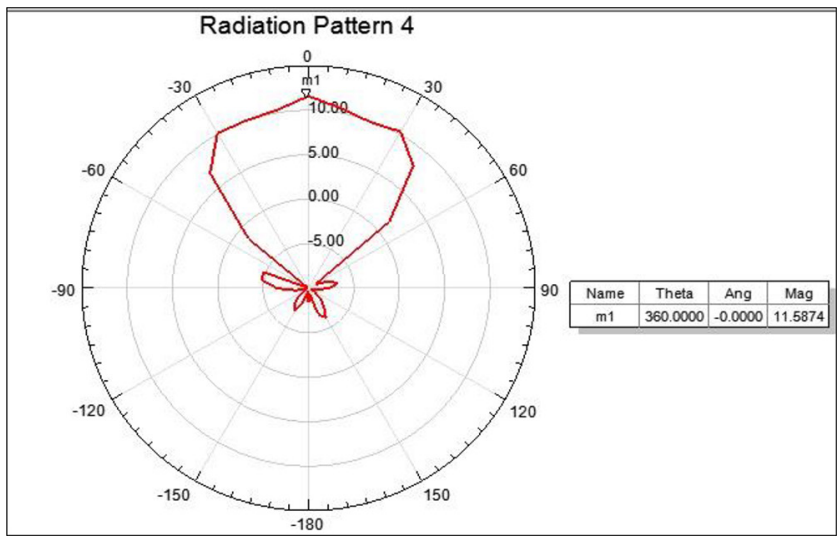

Figure 12. Radiation pattern of $4 \times 4$ patch array antenna (Figure 3).

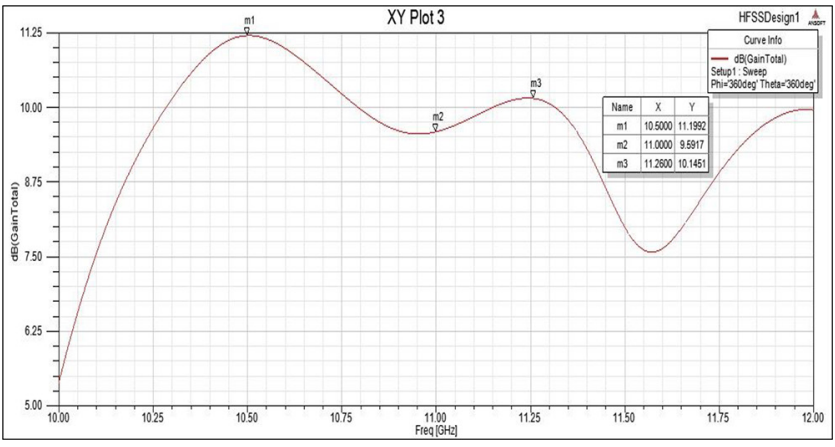

Figure 13. Gain $v s$ Frequency of $4 \times 4$ patch array antennas (Figure 3). 
Figure 3. In comparison to previous design the gain is increased by $1 \mathrm{~dB}$. The corresponding hardware design is shown in Figure 3. Multiband feature is observed in this configuration also.

Figure 14-16 design shows the different measurement parameters of $4 \times 4$ modified patch array antenna shown in Figure 4. Its hardware design is shown in Figure 4. The gain is decreased by a minute value but the current distribution and return loss value improves to a larger extent.

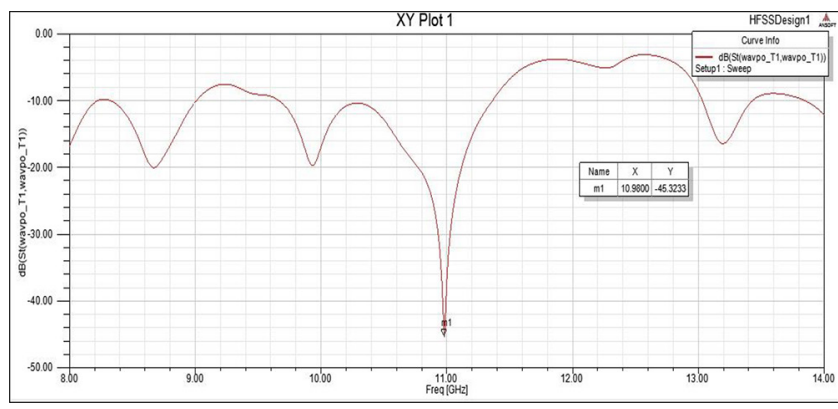

Figure 14. S11 parameter of $4 \times 4$ modified patch array antenna (Figure 4).

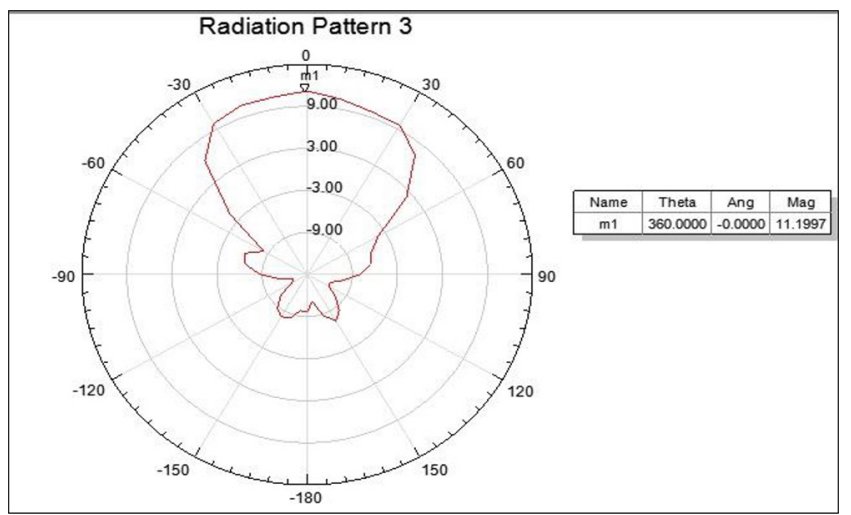

Figure 15. Radiation pattern of $4 \times 4$ modified patch array antenna (Figure 4).

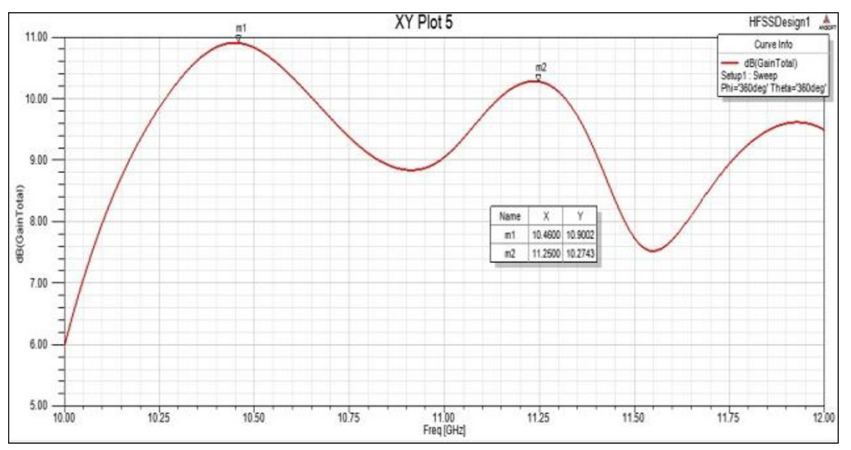

Figure 16. Gain $v s$ frequency of $4 \times 4$ modified patch array antenna (Figure 4).

\section{Conclusion}

Different configurations of array antenna are shown in this study. Their performance is also shown in the previous section. The improvement is the reduction in ground structure size. The second achievement is the combination of series and corporate feed. This design helps in better current distribution over the patched and also minimizes the return loss to a larger extent. The future scope of this design is it can be further extended 10x10 and even 15x15 to match the gain with that of the dish antenna. Once the gain is achieved experiment can be done for replacing existing dish with that of the patch array. The benefit will be size and cost reduction and can be kept even in a small place.

\section{References}

1. Huque TI, Hosain K, Islam S, Chowdhury A. Design and performance analysis of microstrip arrayantennas with optimum parameters for $\mathrm{x}$-band applications, International Journal of Advanced Computer Science and Applications. 2011; 2(4):1-7.

2. Paul LC, Sultan N. Design simulation and performance analysis of a line feed rectangular micro-strip patch antenna, International Journal of Engineering Sciences and Emerging Technologies. 2013; 4(2):1-10.

3. Nawale PA, Zope RG. Design and Improvement of microstrip patch antenna parameters using defected ground structure, International Journal of Engineering Research and Applications. 2014; 4(6):1-7.

4. Mezaal YS. New compact microstrip patch antennas design and simulation results, Indian Journal of Science and Technology. 2016; 9(12):1-6. https://doi.org/10.17485/ijst/ 2016/v9i12/85950.

5. Rameswarudu ES, Sridevi PV. A novel triple band planar microstrip patch antenna with defected ground structure, Indian Journal of Science and Technology. 2016; 9(3):1-5.

6. Chieh JCS, Pham AVA. Bidirectional microstrip x-band antenna array on liquid crystal polymer for beam forming application, IEEE Transactions on Antennas and Propagation. 2013; 61(6):3364-68. https://doi.org/10.1109/ TAP.2013.2249032.

7. Roy AA, Môm JM, Igwue GA. Enhancing the bandwidth of a microstrip patch antenna using slots shaped patch, American Journal of Engineering Research. 2013; 2(9):23-30. 